\title{
Experimental study of microbial enhanced oil recovery in oil-wet fractured porous media
}

\author{
Amin Abolhasanzadeh, Ali Reza Khaz'ali*, Rohallah Hashemi, and Mohammadhadi Jazini \\ Department of Chemical Engineering, Isfahan University of Technology, Isfahan 84156-83111, Iran
}

Received: 9 May 2019 / Accepted: 1 September 2020

\begin{abstract}
Without Enhanced Oil Recovery (EOR) operations, the final recovery factor of most hydrocarbon reservoirs would be limited. However, EOR can be an expensive task, especially for methods involving gas injection. On the other hand, aqueous injection in fractured reservoirs with small oil-wet or mixed-wet matrices will not be beneficial if the rock wettability is not changed effectively. In the current research, an unpracticed fabrication method was implemented to build natively oil-wet, fractured micromodels. Then, the efficiency of microbial flooding in the micromodels, as a low-cost EOR method, is investigated using a new-found bacteria, Bacillus persicus. Bacillus persicus improves the sweep efficiency via reduction of water/oil IFT and oil viscosity, in-situ gas production, and wettability alteration mechanisms. In our experiments, the microbial flooding technique extracted $65 \%$ of matrix oil, while no oil was produced from the matrix system by water or surfactant flooding.
\end{abstract}

\section{Introduction}

More than $20 \%$ of the World's oil and gas reserves occur in naturally fractured reservoirs [1]. However, because of the complexity of the fractured porous media, production from fractured reservoirs has remained a big challenge in the petroleum industry [2]. Fractured reservoirs are known to have initial high flow rates, which rapidly decline, and low ultimate recovery [3]. Specifically, in oil-wet/mixed-wet fractured formations, the final recovery factor is commonly less than $25 \%$, while it can reach $45 \%$ in water-wet fractured reservoirs [3].

In order to increase the ultimate recovery, secondary and tertiary recovery operations may be considered. However, as case histories confirm, the use of water injection in those operations would have a poor efficiency if the matrices are oil-wet/mixed-wet [3]. This is because the injected water preferentially enters the high permeability fractures and if the height of the matrix blocks is smaller than the threshold height, and block-block interactions $[4,5]$ are minimal, no oil from the matrices will be produced [5]. As a result, water only displaces the oil in the fractures, and since the fracture porosity is negligible compared with that of the matrix, only a small fraction of the oil in place can be produced by water injection based methods.

In oil-wet/mixed-wet fractured reservoirs, gas injectionbased techniques showed more prominent results in increasing the oil recovery $[3,6]$. Nevertheless, such methods are

\footnotetext{
* Corresponding author: arkhazali@cc.iut.ac.ir
}

generally more expensive than water injection, which makes them less attractive [7]. Therefore, improving the performance of water injection based methods in the oil-wet/ mixed-wet fractured reservoirs has been an attractive research topic [8-16]. Such improvement can be achieved by alkaline/surfactant injection (which leads to the reduction of the water/oil interfacial tension, capillary pressure and threshold height, creation of water/oil emulsions, and alteration of the matrix wettability) [17, 18], polymer injection (which results in the enhancement of the mobility ratio) [18], and low salinity water injection (which causes wettability alteration) [19]. However, none of these EOR methods are environmentally friendly, and exiting water injection facilities may be required to be modified in order to implement them [20].

Microbial Enhanced Oil Recovery (MEOR) is an alternative tertiary recovery technique that does not include injecting toxic chemicals into the petroleum reservoir. In this method, bacteria are injected into the reservoir, or if the bacteria already exist in the reservoir, only their required nutrients are injected into the porous medium. The bacteria grow inside the reservoir, and improve the sweep efficiency by the following mechanisms [20]:

Reduction of interfacial tension.

If the bacteria can produce biosurfactants, they cause the water/oil interfacial tension to decrease. It leads to the reduction of the capillary pressure and the threshold height within the matrices, which in turn promotes the oil production from them [5]. Also, biosurfactants can alter the matrix wettability [21], and hence, stimulate oil production. The 
same processes take place in chemical surfactant flooding, however, in chemical surfactant flooding, the surfactant initially penetrates the matrix via the molecular diffusion mechanism [22], while in the bacterial flooding, the penetration is accelerated by the chemotaxis [23]. Furthermore, the existence of the biosurfactant in the fracture system leads to the formation of water/oil emulsions, which boosts oil recovery.

Selective plugging.

Because of the large contrast of permeability between matrix and fracture, any injected fluid would rather flow into the fracture network. The high permeability of the fractures results in low pressure gradient within the reservoir, which limits the viscous force [2] and early breakthroughs of the injectant at the production wells. In the MEOR process, the injected bacteria in the fracture network reduce its permeability by the production of biomass. Additionally, some strains of bacteria can produce biopolymer, which leads to a further reduction of the fracture permeability. As a result, the injectant is forced to sweep the oil in the low permeable areas (like matrices) with a higher viscous force.

Reduction of oil viscosity.

Particular types of bacteria can produce gas and solvents, which can dissolve in the oil and reduce its viscosity. Decreasing oil viscosity results in enhancement of the mobility ratio and the sweep efficiency, consequently.

Biodegradation of the oil.

Certain strains of bacteria can degrade the paraffin content in the oil, which lead to the reduction of the oil viscosity and increasing its API. Also, biodegradation can increase the rock permeability by the elimination of the deposited long-chain paraffin on the surface of the rock [24].

Wettability alteration.

Production of biosurfactants and oil biodegradation lead to the alteration of the wettability towards more waterwet states [25, 26]. Wettability alteration accelerates oil production from the matrix system by improving the imbibition rate of injected water into the matrices.

Although not all of these mechanisms can be invoked by one type of bacterium, the potential of microbial flooding in enhancing the oil recovery from oil-wet/mixed-wet fractured reservoirs is undeniable. However, despite existing rich literature on microbial enhanced oil recovery [24, 27-34], few researches have been performed on the MEOR in fractured porous media [35-40], among which, only one has been done on oil-wet fractured system [41].

In particular, Zekri and Almehaideb [40], injected a Bacillus sp. bacteria into artificially fractured, limestone outcrop samples. They did not perform the aging process on the dried samples. Therefore, it has to be assumed that the samples were extremely water-wet. Their experiments confirmed the effects of selective plugging. Moreover, they concluded that the angle of the fractures with respect to the flow direction has a strong effect on the performance of water flooding and MEOR.

Soudmand-Asli et al. [39] studied MEOR by injecting two different strains of bacteria (Leuconostoc mesenteroides, Bacillus subtilis) into water-wet glass micromodels. They imitated the fractured porous media by etching large channels inside a fine-scale pore network. However, their pattern of fractures does not resemble any accepted model $[42,43]$ of fractured reservoirs, i.e., the flow cannot bypass the matrix by flowing inside the fractures; except in one of their models, where applying MEOR could only add 3.2\% to the final recovery factor. In addition, they did not test the performance of the employed bacteria in environments with high levels of salinity.

Nourani et al. [37], Biria et al. [36], and Al-Hattali et al. [35] performed similar experiments in strongly water-wet fractured systems. In such systems, in addition to the mechanisms which can be initiated by bacteria, spontaneous imbibition plays an important role in increasing the oil recovery.

Xiao et al. [41] studied MEOR in glass micromodels. They similarly reconstructed the fractured porous media as Soudmand-Asli et al. [39]. The micromodels were saturated by crude oil and aged for 7 days to become oilwet. After that, they performed two successive stages of injection on the micromodels, in which the micromodels were injected with water, and then, with collected bacteria from the production wells of Chaoyanggou reservoir, respectively. They reported that approximately $57 \%$ of the initial oil in place could be recovered by water flooding only, and microbial injection after the water flooding could marginally increase the recovery by nearly $7 \%$. However, they have not explained how in an oil-wet fractured system, without the effects of gravity, such a large fraction of Initial Oil In Place (IOIP) can be produced only by water flooding. In such a system and for the typical range of capillary numbers, only the fractures are flooded by water. Since fracture porosity is much smaller than the matrix porosity [5], such levels of recovery cannot be achieved by water flooding in a real oil-wet fractured porous medium.

In the current research, the enhanced oil recovery from natively oil-wet micromodels mimicking fractured reservoir rocks has been examined. Micromodels have been frequently used for visualizing the fluids flow in porous media. Utilizing micromodels to study MEOR makes the clear observation and characterization of the distribution of the fluids and bacteria possible [44]. Nevertheless, micromodels have been commonly built from glass, which is a strongly water-wet material. In addition, the current fabrication methods are either expensive or unable to control the depth and the profile of the fluids paths within the micromodels [45, 46]. Here, we employed a super cheap, unpracticed method for the fabrication process of micromodels from plexiglass or Poly (methyl methacrylate). Plexiglass is natively oil-wet, and the fluid paths on its substrates can be precisely ablated by $\mathrm{CO}_{2}$ laser. Since it is believed that most of the reservoir rocks are water-wet [47], the use of plexiglass for microfluidics applications in petroleum engineering is rare due to the requirement of specialized treatments to change its original wettability from oil-wet to water-wet. However, they are highly suitable for the reconstruction of oil-wet porous media. This is due to the fact that despite glass micromodels, they do not need to be aged or injected by specialized chemicals to become oil-wet. To the knowledge of the authors, plexiglass micromodels have not been used to study oil recovery from oil-wet fractured porous media. 
To perform MEOR on the micromodels, a newly found strain of bacteria named Bacillus persicus, isolated from the hypersaline lake Aran-Bidgol in Iran [48], has been utilized. Bacillus persicus can live in saline environments and is able to produce $\mathrm{H}_{2} \mathrm{~S}$ [48]. The cells can form endospores under harsh conditions of oil reservoirs. Therefore, they can survive there.

Bacillus persicus improved the performance of the tertiary recovery by lowering the IFT, altering the wettability, and reducing the oil viscosity. Then we compared the performance of MEOR with water flooding and surfactant flooding. The results confirm that the MEOR has much more potential for the oil recovery from oil-wet/mixed-wet fractured reservoirs than the other water injection based EOR methods.

\section{Materials and methods}

\subsection{Micromodel}

CorelDRAW ${ }^{\circledR} \mathrm{X} 8$ vector graphics suit was used to create the porous pattern of the micromodel, as shown in Figure 1. It was tried to maximize the similarity between the micromodel porous pattern and that of fractured reservoir rocks. Therefore, the designed pattern involved an unstructured network of connecting and dead-end throats, pores with different coordination numbers, and a set of connected fractures. The fracture system has been implemented in compliance with Warren and Root [43] model, in which both the fracture and matrix systems can carry the flow. However, most of the flow would pass through the fractures, since they are designed to have much more conductivity compared with the pores and throats.

The design pattern has been ablated by $\mathrm{CO}_{2}$ laser on a $15 \times 10 \mathrm{~cm}$ plexiglass substrate. The dimensions of the fluid paths within the micromodel are given in Table 1 . In order to achieve the properties in Table 1, the laser power was set to $30 \mathrm{~W}$. The scan speed of the laser beam was variable, depending on the required depth. After the ablation process, the plexiglass sheet was washed with water and soap; then, it was placed in a $70{ }^{\circ} \mathrm{C}$ oven for 5 min to be dried. Then it was coupled with another plexiglass substrate, and the coupled sheets were placed under compression in an electric furnace to undergo thermal compression bonding procedure. The furnace temperature was raised from $120{ }^{\circ} \mathrm{C}$ to $200{ }^{\circ} \mathrm{C}$ in a stepwise manner. The required duration of the thermal compression bonding for a perfect bond was determined to be $60 \mathrm{~min}$. The final form of the bounded micromodel is depicted in Figure 2.

In order to test the precision of the laser ablation procedure, the depth of the pore/throats and fracture system has been investigated by Field Emission Scanning Electron Microscopy (FESEM). The images taken by FESEM are shown in Figure 3, which shows the geometry of ablated pore spaces. The effects of the laser ablation procedure, which causes a near-instantaneous phase change in the plexiglass substrate, can be seen at the edges of the microstructures. Although such effects lead to about $10 \%$

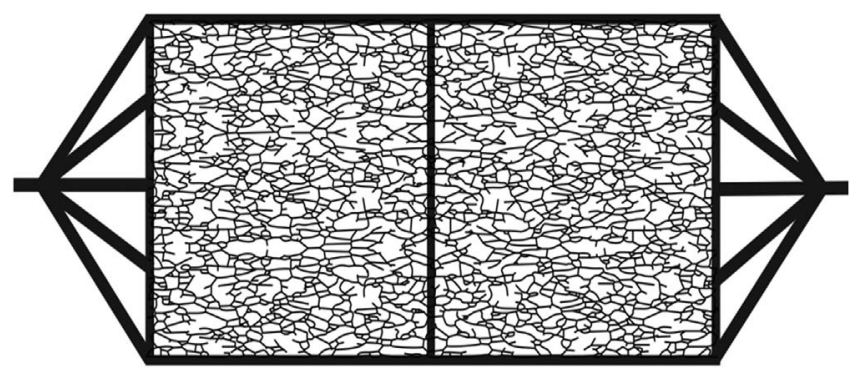

Fig. 1. The porous pattern of the micromodel.

Table 1. The key dimensions of the fabricated micromodel.

\begin{tabular}{lc}
\hline Property & Value \\
\hline Pattern dimensions & $15 \times 6 \mathrm{~cm}$ \\
The third dimension of the plexiglass & $3 \mu \mathrm{mm}$ \\
substrates & \\
Pores/throats average width & $286 \mu \mathrm{m}$ \\
Pores/throats average depth & $360 \mu \mathrm{m}$ \\
Fracture average width & $2000 \mu \mathrm{m}$ \\
Fracture average depth & $800 \mu \mathrm{m}$ \\
\hline
\end{tabular}

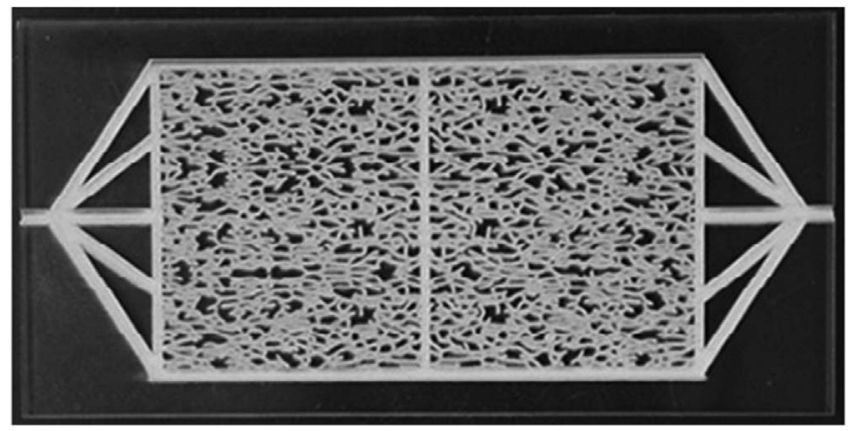

Fig. 2. The final form of the plexiglass micromodel.

variation in the dimensions of the fluid paths, performing careful measurements on the images confirms the values of Table 1. Nevertheless, the irregular shape of microstructure edges increases the resemblance of the micromodel fluids paths to those of real porous media of a reservoir.

The wettability of the fabricated micromodel has been evaluated by the contact angle experiments. In these experiments, droplets of water and oil were placed on the surface of the plexiglass substrate in the presence of air, and the contact angle of the droplets was measured. As it is depicted in Figure 4, the micromodel surface obviously preferred the oil phase, since the contact angle of the oil $\left(31.77^{\circ}\right)$ was less than the contact angle of the water $\left(76.10^{\circ}\right)$. 


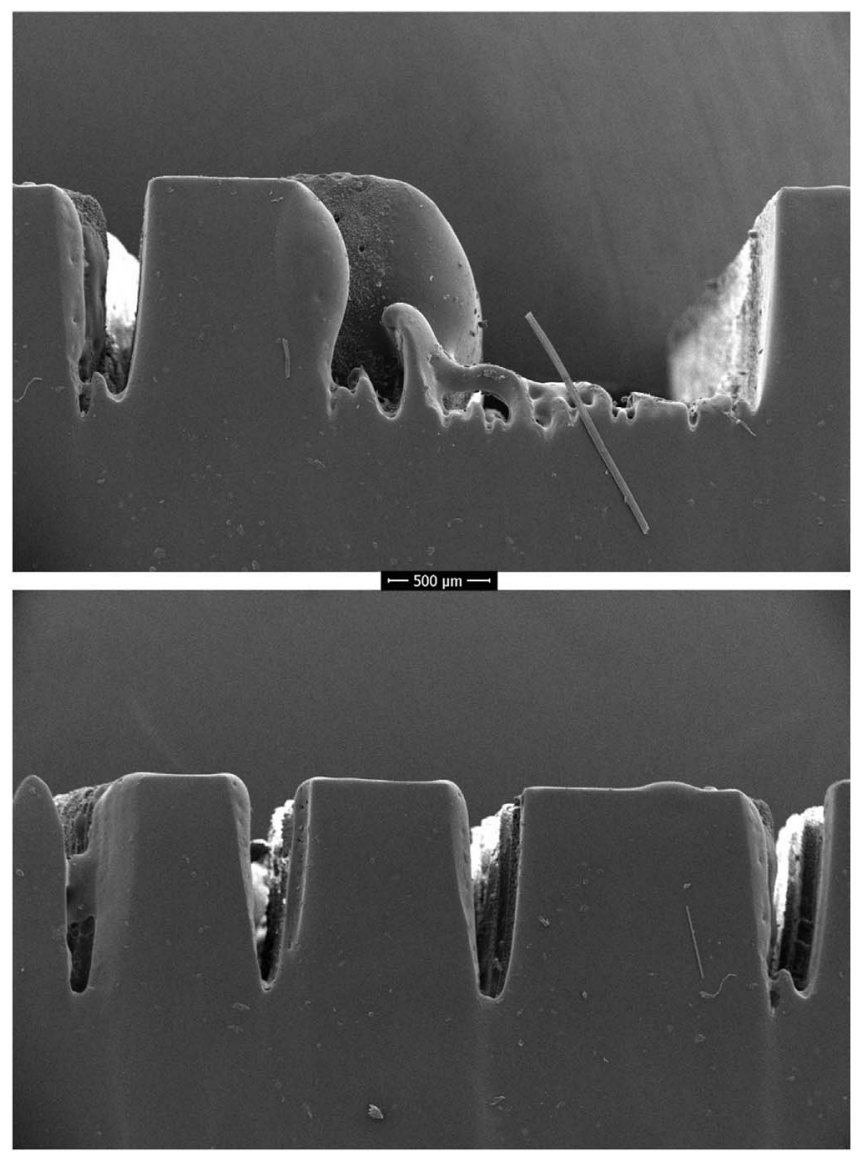

Fig. 3. FESEM images of fracture profile (above) and pore/ throats profile (below).

\subsection{Strain, medium, and cultivation conditions}

Bacillus persicus was purchased from Persian type collection culture (Strain number: IBRC-M 10115). The lyophilized cells were activated and then cultivated in the medium contained $(\mathrm{g} / \mathrm{L}): \mathrm{NaCl}, 20.0 ; \mathrm{MgCl}_{2} \cdot 6 \mathrm{H}_{2} \mathrm{O}, 3.0$; $\mathrm{MgSO}_{4} \cdot 7 \mathrm{H}_{2} \mathrm{O}, 5.0 ; \mathrm{CaCl}_{2} \cdot 2 \mathrm{H}_{2} \mathrm{O}, 0.05 ; \mathrm{KCl}, 0.5$; peptone from meat, 5 ; meat extract, 2 and yeast extract, 1 . The initial $\mathrm{pH}$ of the medium was adjusted to $7.5 .90 \mathrm{~mL}$ of autoclaved medium was inoculated with $10 \mathrm{~mL}$ of previously prepared culture (optical density of ca. 1). The culture was incubated at $35{ }^{\circ} \mathrm{C}$ ( Jal Tajhiz, JSTDL 40, Iran). Since the growth curve of the bacteria has not been reported yet, every hour, a sample was taken, and the optical density of the broth was measured at $600 \mathrm{~nm}$ (Rayleigh, UV-1601, China). Doing so, the growth curve, as well as the end of the exponential phase, were determined. The broth that was used for MEOR experiments was at the end of the exponential phase.

\subsection{Experimental procedure}

In order to compare the efficiency of different types of water-based enhanced oil recovery in an oil-wet fractured porous medium, three experiments were performed using the fabricated plexiglass micromodel. The water injection experiment was used as our based case scenario.

\subsubsection{Experimental setup}

The experimental setup is depicted in Figure 5. The fluids can be injected into the micromodel using a high precision syringe pump (Safir Soraya Sepahan, SP 120, Iran), and the exiting fluids would be collected in the drain flask. A uniform light source is placed below the micromodel, and a camera is fixed above it to take images with a predetermined interval automatically. The images are then sent to a computer, where the fluids saturation is found using image processing techniques. All experiments have been performed at $25^{\circ} \mathrm{C}$ and atmospheric pressure.

\subsubsection{Establishing initial saturation}

Before any test, the micromodel was saturated with brine. Then, a selected crude oil from Marun oil field (southwest Iran) was used to inject into the micromodel to displace the brine, as shown in Figure 6. The properties of employed fluids are given in Table 2. After each experiment, the micromodel was washed or replaced, and the process of initial saturations establishment was repeated for the next run of experiments.

\subsubsection{Water injection}

In order to test the effectiveness of water injection in fractured porous media, a test was carried out to displace the oil by water injection only. For this purpose, 4 PVs of the brine were injected into the micromodel at a rate of $0.008 \mathrm{~mL} / \mathrm{min}$. In this experiment, the camera was set to take pictures every $45 \mathrm{~min}$.

\subsubsection{Microbial injection}

Using a sterile syringe in the pump, $1 \mathrm{PV}$ of a mixture of $50 \%$ culture and $50 \%$ fresh medium has been injected into the oil-saturated micromodel at a rate of $0.008 \mathrm{~mL} / \mathrm{min}$. Then, the injection was stopped, and the system was monitored for 3 days, during which the camera takes images from the micromodel every $45 \mathrm{~min}$. After three days, $3 \mathrm{PVs}$ of the brine are injected into the micromodel, and the oil recovery is measured.

In order to determine the effects of Bacillus persicus on oil, several $50 \mathrm{~mL}-$ Falcon tubes were filled by $10 \mathrm{~mL}$ of crude oil, $6 \mathrm{~mL}$ of nutrient solution, and $6 \mathrm{~mL}$ of bacterial culture. Every $8 \mathrm{~h}$ (up until $72 \mathrm{~h}$, the same duration as the bacterial injection experiment), the mixture in one of the tubes was centrifuged for $10 \mathrm{~m}$ at $3000 \mathrm{RPM}$ to separate the crude oil, then, the IFT of the oil and brine was measured using the pendant drop method. In addition, the viscosity of the separated crude oil at the start and the end of the experiment was measured using a rolling ball viscometer.

For determining the degree of wettability alteration resulted from Bacillus persicus, a clean plexiglass sheet was kept in a mixture of $50 \%$ culture and $50 \%$ fresh medium for three days. After that, the contact angle of the oil (from 


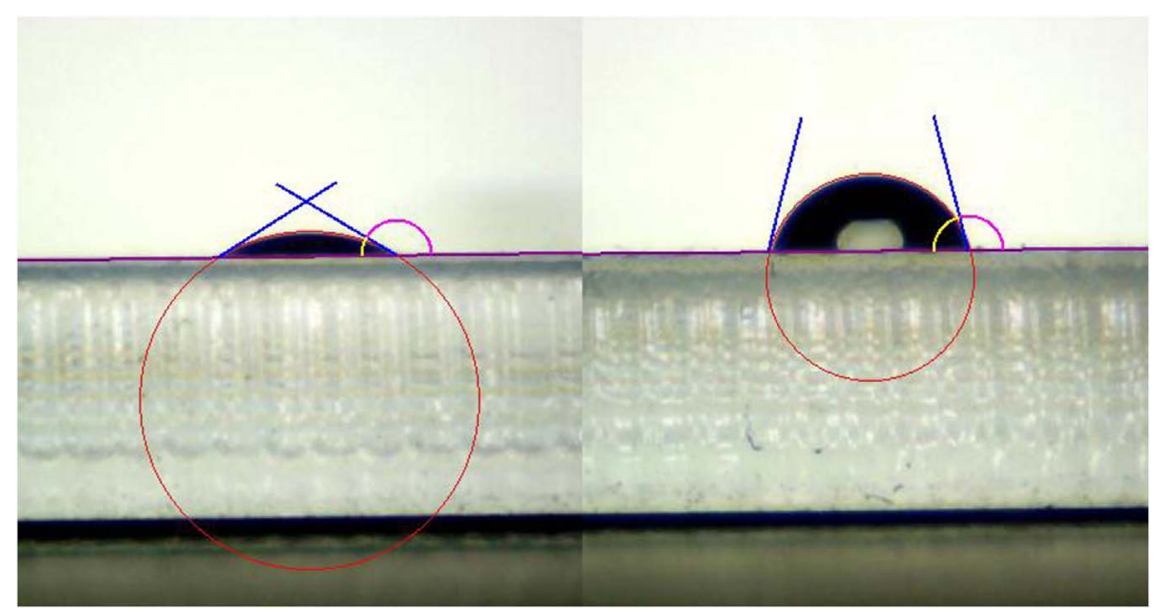

Fig. 4. Contact angle measurement of oil droplet (left) and water droplet (right) on the micromodel surface.

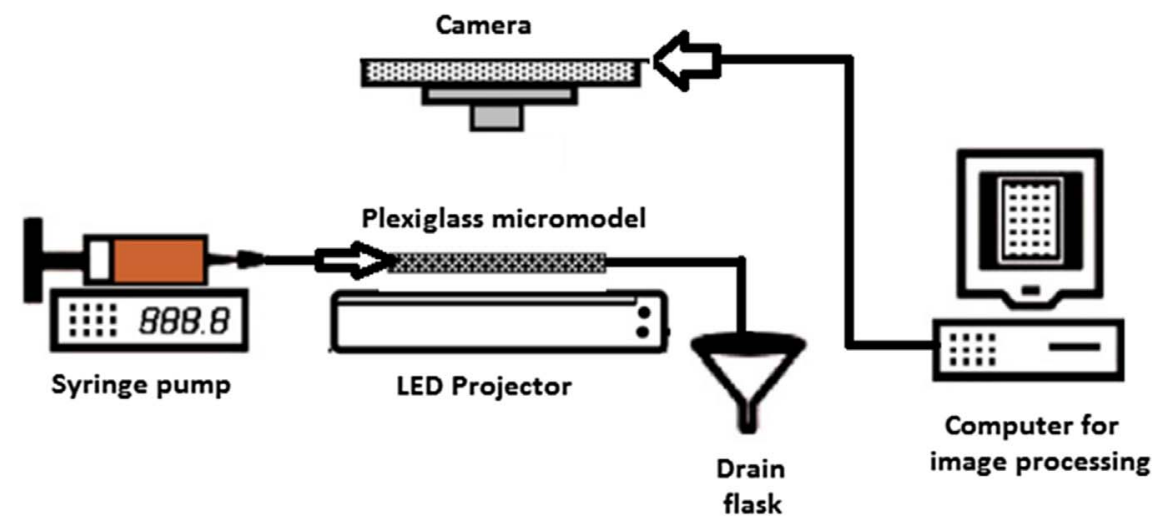

Fig. 5. The experimental setup schema.

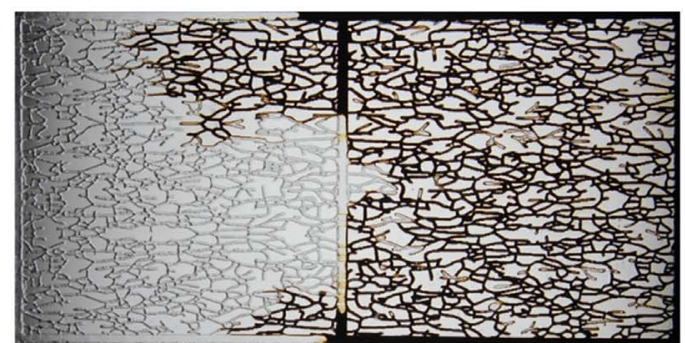

(a)

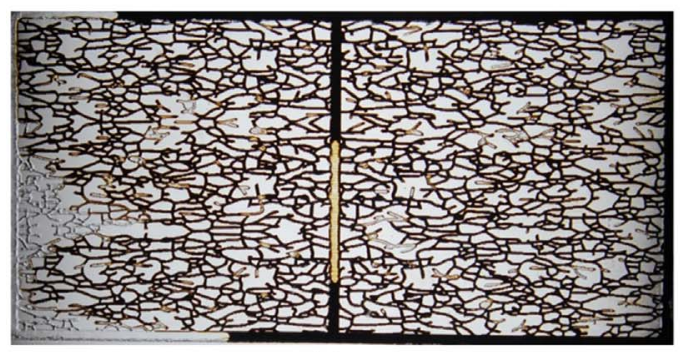

(c)

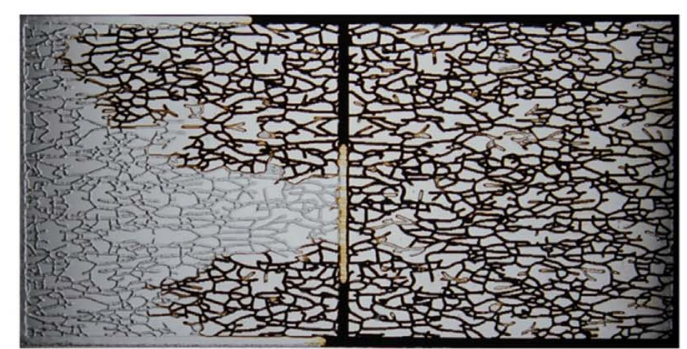

(b)

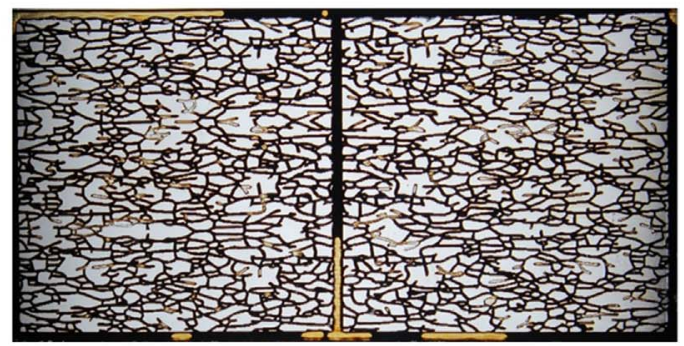

(d)

Fig. 6. Four stages of saturating the micromodel with Marun crude oil. Trapping of the non-wetting phase (brine) within the fractures and dead-end throats is visible. 
Table 2. The properties of used fluids.

\begin{tabular}{lcc}
\hline Fluid & Property & Value \\
\hline Crude oil & Viscosity in $25{ }^{\circ} \mathrm{C}$ & $7.3 \mathrm{cP}$ \\
& Asphaltene content & $0.4 \mathrm{wt} . \%$ \\
Brine & Specific gravity & 0.8613 \\
& Dissolved $\mathrm{NaCl}$ & $10 \mathrm{wt} . \%$ \\
\hline
\end{tabular}

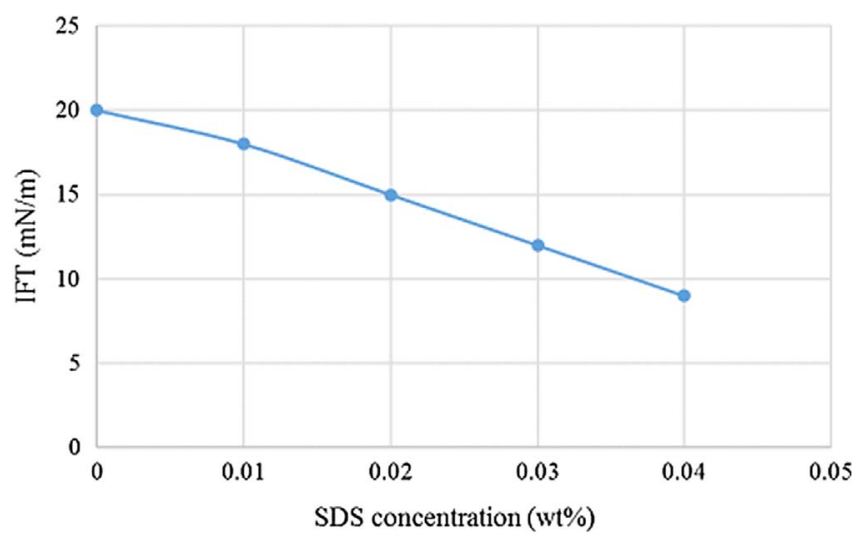

Fig. 7. The IFT of SDS solutions with the oil.

the Falcon tubes) on the plexiglass substrate was measured in the presence of the brine.

\subsubsection{Surfactant injection}

The goal of this experiment was to compare the efficiency of surfactant flooding to that of microbial flooding. The utilized surfactant was SDS (Sodium Dodecyl Sulfate), which is commonly used in the chemical injection EOR processes. In order to perform a standard comparison, a solution of SDS in water whose IFT would be the same as what was obtained in the Bacillus persicus experiment had to be prepared. To this end, five solutions of SDS in water with different concentrations were prepared, and their IFT with the oil was measured, as depicted in Figure 7. By interpolating the data in Figure 7, the desired SDS concentration was calculated to be 0.017 wt \% Additionally, in order to investigate the maximum capability of SDS for displacing the oil, we repeat the injection experiment using a solution of SDS having Critical Micelle Concentration $(\mathrm{CMC}=0.25 \mathrm{wt} \%$ [49]). All parameters of the surfactant injection test were identical to the water injection experiment.

\section{Results and discussion}

\subsection{Bacillus persicus growth curve}

The growth curve of Bacillus persicus is given in Figure 8, which shows the bacterium reaches the end of the exponential phase (start of stationary phase) after $21 \mathrm{~h}$. After that, due to the exhaustion of the substrate, the cell concentration started to decrease. The cells at the end of the exponential phase were used for subsequent experiments and injection.

\subsection{EOR outcomes}

Image analysis indicates that no oil from the matrix was produced during water injection. The same result was achieved in both surfactant (SDS) injection experiments; since the injectant can only sweep the oil in the fracture system. The same situation is expected to occur in oil-wet/mixed-wet fractured reservoirs, where the viscous forces fail to provide a pressure difference more than the capillary threshold pressure through the matrix blocks. Therefore, because of the low porosity of the fractures, such EOR methods cannot extract an acceptable portion of IOIP.

Despite water and surfactant injection, the microbial injection could extract up to $65 \%$ of IOIP in the matrix, as shown in Figure 9. Figure 10 shows the incremental movement of the oil in the matrix to the fractures during the MEOR experiment. Higher resolution images can also

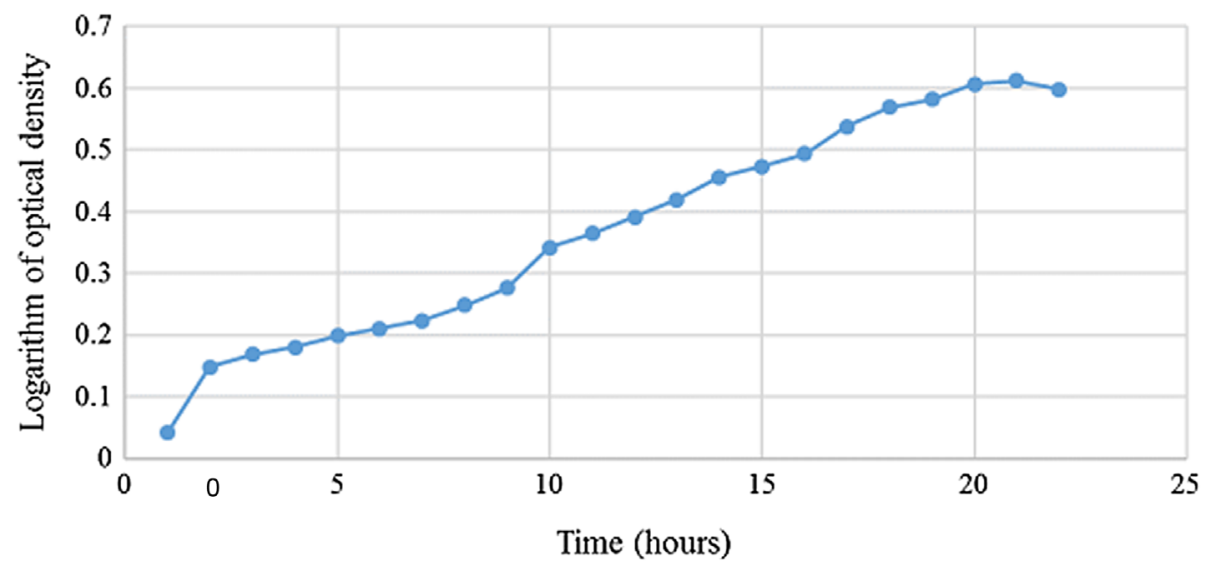

Fig. 8. Bacillus persicus growth curve. 


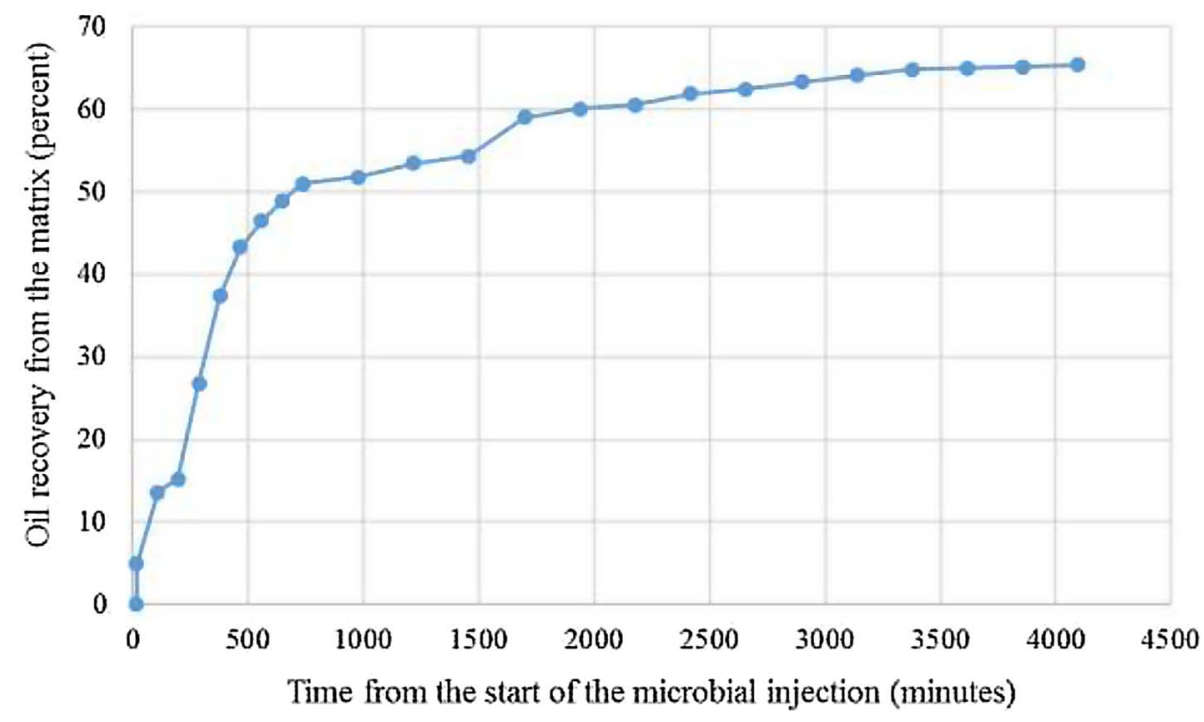

Fig. 9. The produced fraction of IOIP in the matrix during the MEOR procedure.

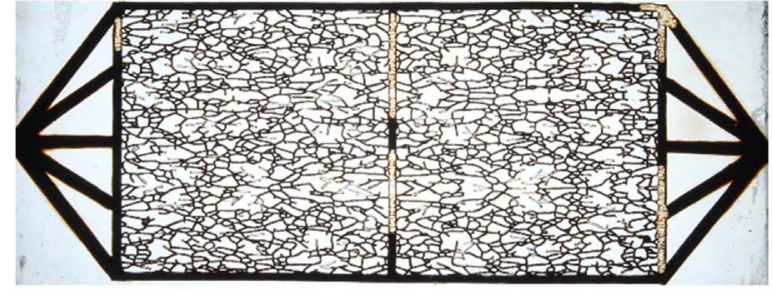

(A)

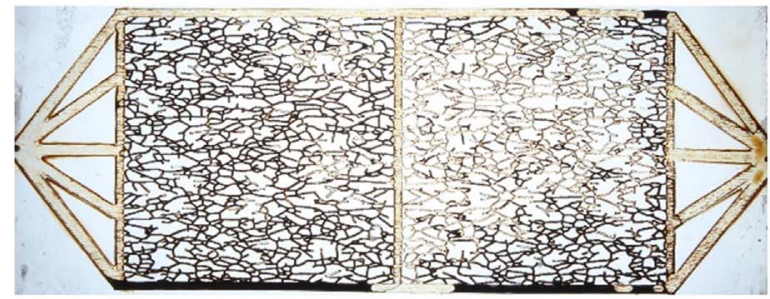

(C)

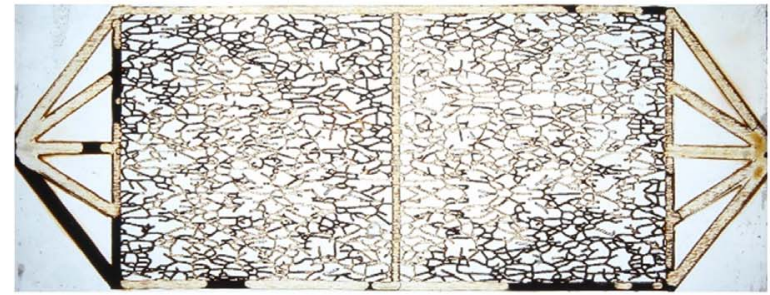

(E)

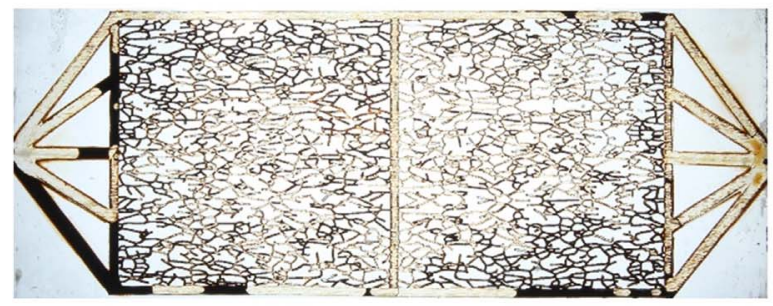

(G)

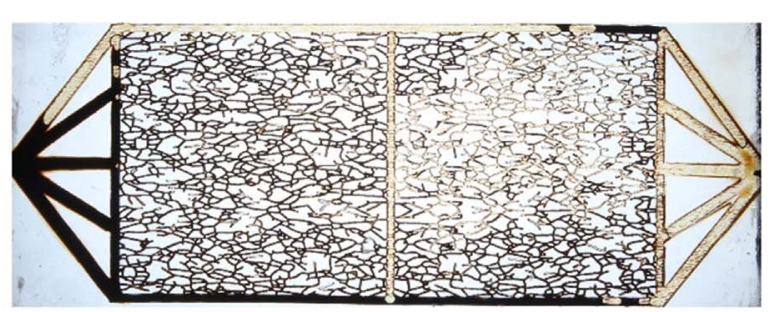

(B)

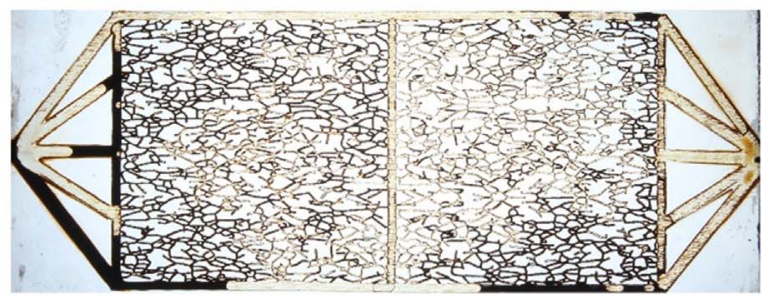

(D)

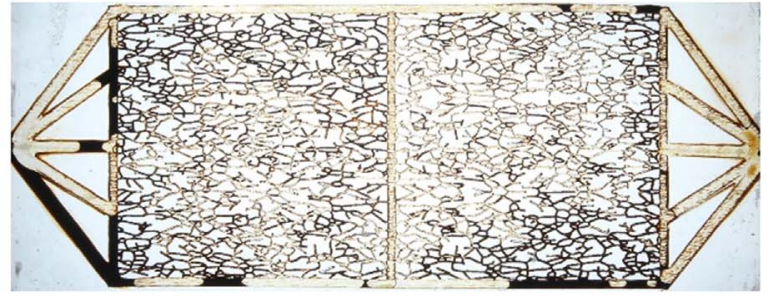

(F)

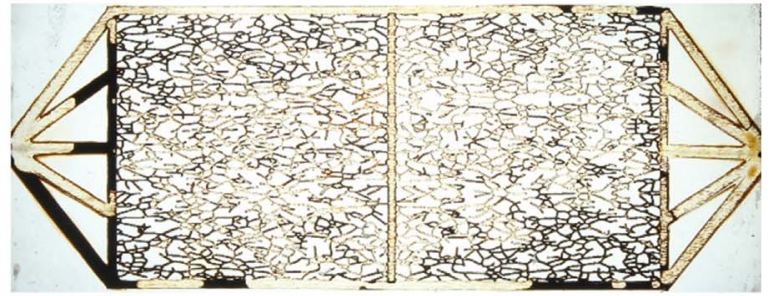

(H)

Fig. 10. The stages of MEOR within the micromodel. Note that the oil is being pushed out from the matrix. 


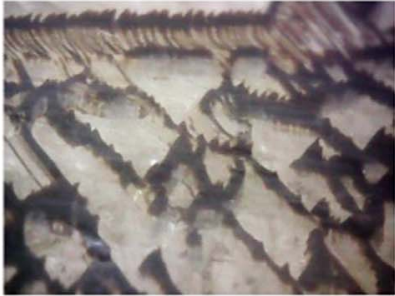

(a)

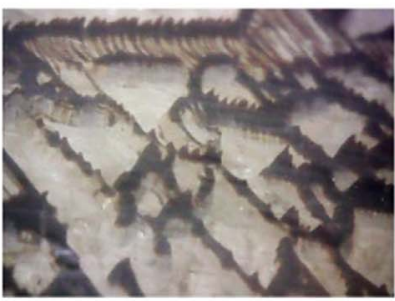

(c)

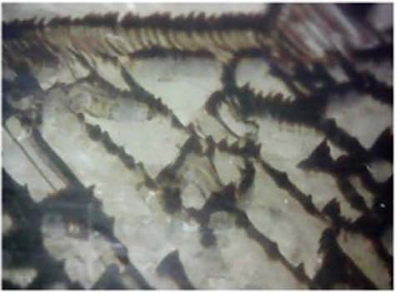

(e)

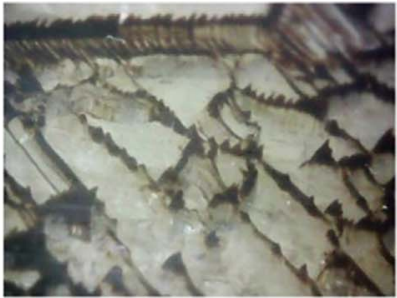

(g)

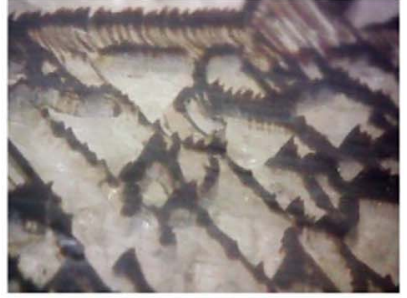

(b)

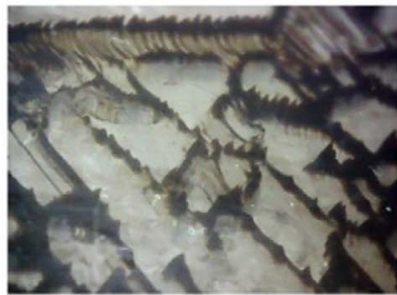

(d)

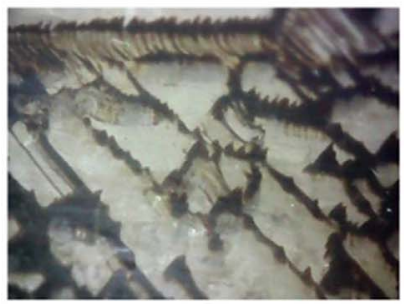

(f)

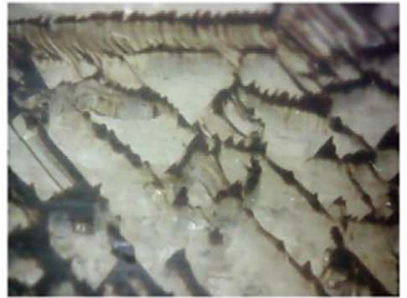

(h)
Fig. 11. (a)-(h) High-resolution images of the interface of fracture (the wider channel at the above) and matrix (narrower paths below) in the micromodel at different times of the experiment, showing the oil recovery from the matrix.

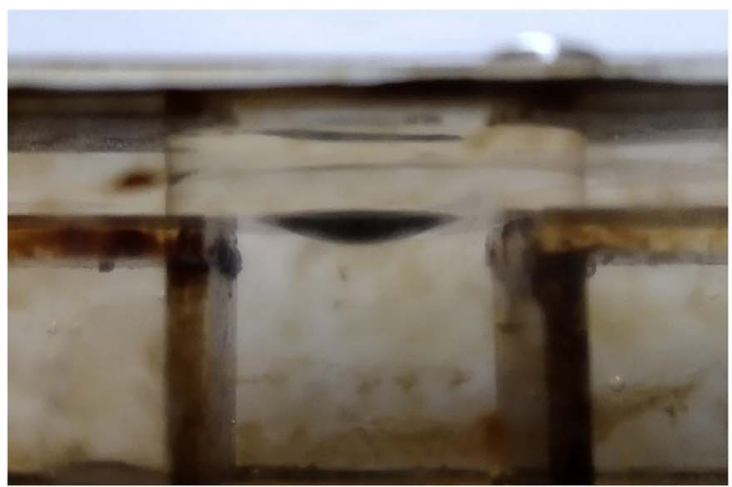

Table 3. The results of viscosity, IFT and contact angle measurements before and after treating the fluids and the micromodel with Bacillus persicus.

\begin{tabular}{lcc}
\hline Parameter & Original value & $\begin{array}{c}\text { The value after } \\
\text { microbial treatment }\end{array}$ \\
\hline Viscosity & $7.5 \mathrm{cP}$ & $3.5 \mathrm{cP}$ \\
$\begin{array}{l}\text { Dynamic } \\
\text { brine/oil IFT }\end{array}$ & $20.0843 \mathrm{mN} / \mathrm{m}$ & $15.8479 \mathrm{mN} / \mathrm{m}$ \\
Contact angle & $150^{\circ}$ & $46.84^{\circ}$ \\
\hline
\end{tabular}

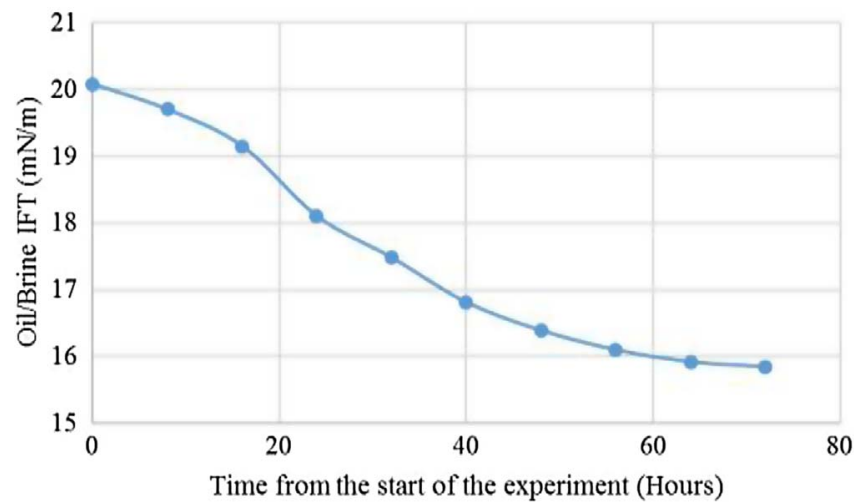

Fig. 12. Oil/Brine dynamic IFT.

be observed in Figure 11, where the bacterial injectant/oil front movements at the matrix/fracture interface are more clear.

The results of viscosity, IFT, and wettability tests are expressed in Table 3, and the dynamic brine/oil IFT plot is shown in Figure 12. The results of the dynamic IFT tests demonstrate the IFT reduction was faster at the start of the experiment when the bacterial population was growing. After the exhaustion of the substrate, the population of Bacillus persicus and the rate of biosurfactant production began reducing, and therefore, the oil/brine IFT was virtually stabilized at the end of the experiment.

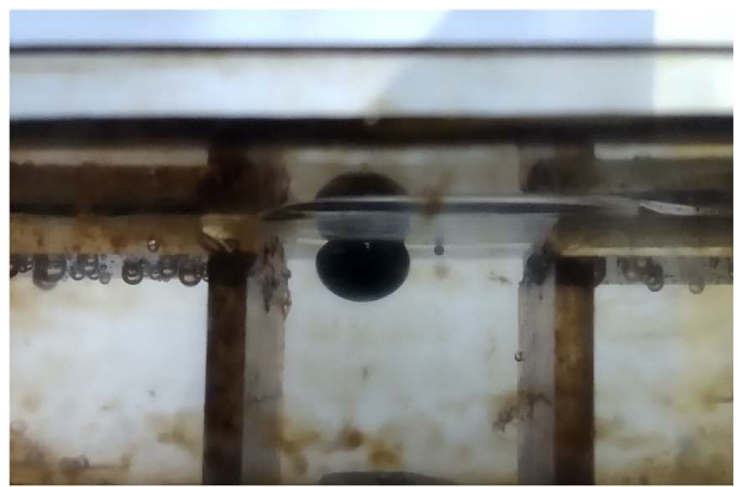

Fig. 13. Contact angle experiment. Left: oil droplet on the surface of untreated plexiglass. Right: oil droplet on the surface of plexiglass treated with the bacterium. 
The images from the contact angle experiments are shown in Figure 13, in which a droplet of oil is placed on the surfaces of treated and untreated plexiglass substrates in the presence of the brine.

From the presented data, it is obvious that Bacillus persicus could successfully move into the matrix, and by altering its wettability, initiated the spontaneous imbibition of water into it. Furthermore, the production of $\mathrm{H}_{2} \mathrm{~S}$ by the bacteria [48] and the increasing cell number in the matrix caused the oil in the matrix to be pushed out to the fracture system. Additionally, it seems that the dissolution of the produced $\mathrm{H}_{2} \mathrm{~S}$ into the oil led to the reduction of oil viscosity and hence, the mobility ratio was enhanced. Reduction of water/oil interfacial tension caused decreasing the opposing capillary forces which further eased the oil recovery.

\section{Summary and conclusion}

In this paper, we presented a method to construct natively oil-wet, inexpensive micromodels from plexiglass (PMMA) substrates. Using such a method, we were able to reconstruct a dual porosity-dual permeability oil-wet porous medium, which mimics the oil-wet/mixed-wet fractured rocks. The efficiency of three economic EOR methods, i.e., water injection, surfactant injection, and microbial injection in the fabricated micromodel was compared. The results of the experiments showed that MEOR could successfully extract $65 \%$ of IOIP in the matrix, while two other methods failed to produce any amount of oil from the matrix.

The used bacterium in the MEOR experiments was Bacillus persicus, a salt-tolerate, endospore-forming bacterium, which has been recently identified and isolated. The ability of the bacteria for the production of $\mathrm{H}_{2} \mathrm{~S}$ and their survival (endospore-forming) under harsh conditions have been reported earlier [48]. In this study, these features of the bacteria were exploited for MEOR. The injection of bacterial culture to the porous medium enhanced the mobility ratio, decreased the brine/oil IFT, and altered the wettability of porous medium favorably. All of these mechanisms contributed to the considerable increase in oil recovery.

The results of this research demonstrate the potential of MEOR, as a low-cost EOR method, to improve the final hydrocarbon recovery of oil-wet/mixed-wet fractured reservoirs.

\section{References}

1 Saidi A.M. (1983) Simulation of naturally fractured reservoirs, in: SPE Reservoir Simulation Symposium, 15-18 November, San Francisco, California, Society of Petroleum Engineers.

2 Fern $\emptyset$ M.A. (2012) Enhanced oil recovery in fractured reservoirs, in Introduction to Enhanced Oil Recovery (EOR) Processes and Bioremediation of Oil-Contaminated Sites, IntechOpen, New York.
3 Allan J., Sun S.Q. (2003) Controls on recovery factor in fractured reservoirs: lessons learned from 100 fractured fields, in SPE Annual Technical Conference and Exhibition, 5-8 October, Denver, Colorado, Society of Petroleum Engineers.

4 Saidi A.M., Tehrani D.H., Wit K. (1979) PD 10 (3) mathematical simulation of fractured reservoir performance, based on physical model experiments, in: 10th World Petroleum Congress, 9-14 September, Bucharest, Romania, World Petroleum Congress.

5 van Golf-Racht T.D. (1982) Fundamentals of fractured reservoir engineering, Vol. 12, Elsevier.

6 Uleberg K., Høier L. (2002) Miscible gas injection in fractured reservoirs, in: $S P E / D O E$ Improved Oil Recovery Symposium, 13-17 April, Tulsa, Oklahoma, Society of Petroleum Engineers.

7 El-Banbi A.H., Aly A.M., Lee W.J., McCain Jr. W.D. (2000) Investigation of waterflooding and gas cycling for developing a gas-condensate reservoir, in: SPE/CERI Gas Technology Symposium, 3-5 April, Calgary, Alberta, Canada, Society of Petroleum Engineers.

8 Abbaszadeh M., Rodriguez De-La Garza F., Villavicencio AE (2016) Methodology of foam-surfactant EOR for pilot design studies in naturally fractured reservoirs, in: SPE EOR Conference at Oil and Gas West Asia, 21-23 March, Muscat, Oman, Society of Petroleum Engineers.

9 Badizad M.H., Zanganeh A.R., Dehaghani A.H., Dehaghani S. (2016) Simulation and assessment of surfactant injection in fractured reservoirs: a sensitivity analysis of some uncertain parameters, Iranian J. Oil Gas Sci. Technol. 5, 1, 13-26.

10 Bourbiaux B., Fourno A., Nguyen Q.-L., Norrant F., Robin M., Rosenberg E., Argillier J.-F. (2016) Experimental and numerical assessment of chemical enhanced oil recovery in oil-wet naturally fractured reservoirs, SPE J. 21, 03, 706-719.

11 Mohammed M.N., Hossain M.E. (2016) A numerical investigation on the performance of alkaline-surfactant-polymer flooding in naturally fractured carbonate reservoirs, in: $S P E$ Kingdom of Saudi Arabia Annual Technical Symposium and Exhibition, 25-28 April, Dammam, Saudi Arabia, Society of Petroleum Engineers.

12 Najafabadi N.F., Delshad M., Sepehrnoori K., Nguyen Q.P., Zhang J. (2008) Chemical flooding of fractured carbonates using wettability modifiers, in: SPE Symposium on Improved Oil Recovery, 20-23 April, Tulsa, Oklahoma, Society of Petroleum Engineers.

13 Parra J.E., Pope G.A., Mejia M., Balhoff M.T. (2016) New approach for using surfactants to enhance oil recovery from naturally fractured oil-wet carbonate reservoirs, in: SPE Annual Technical Conference and Exhibition, 26-28 September, Dubai, $U A E$, Society of Petroleum Engineers.

14 Saki M., Khaz'ali A.R. (2017) Influence of surfactant type, surfactant concentration, and salinity on interfacial tension of a brine/live oil/surfactant fluid system: A case study of Iranian Asmari Oil Reservoir, Iranian J. Oil Gas Sci. Technol. 6, 1, 1-16.

15 Sepehri M., Moradi B., Emamzadeh A., Mohammadi A.H. (2019) Experimental study and numerical modeling for enhancing oil recovery from carbonate reservoirs by nanoparticle flooding, Oil Gas Sci. Technol. - Rev. IFP Energies nouvelles 74, 5 .

16 Zaeri M.R., Hashemi R., Shahverdi H., Sadeghi M. (2018) Enhanced oil recovery from carbonate reservoirs by spontaneous imbibition of low salinity water, Pet. Sci. 15, 3, 564-576. 
17 Mayer E.H., Berg R.L., Carmichael J.D., Weinbrandt R.M. (1983) Alkaline injection for enhanced oil recovery - A status report, J. Pet. Technol. 35, 01, 209-221.

18 Sayed Akram N.I., Mamora D. (2011) SPE/DGS Saudi Arabia Section Technical Symposium and Exhibition, in: Simulation study on surfactant-polymer flood performance in fractured carbonate reservoir, 15-18 May, Al-Khobar, Saudi Arabia, Society of Petroleum Engineers.

19 Derkani M., Fletcher A., Abdallah W., Sauerer B., Anderson J., Zhang Z. (2018) Low salinity waterflooding in carbonate reservoirs: Review of interfacial mechanisms, Colloids Interf. 2, 2, 20.

20 Gao C.H., Zekri A. (2011) Applications of microbialenhanced oil recovery technology in the past decade, Energy Sources, Part A 33, 10, 972-989.

21 Wang Y., Xu H., Yu W., Bai B., Song X., Zhang J. (2011) Surfactant induced reservoir wettability alteration: Recent theoretical and experimental advances in enhanced oil recovery, Pet. Sci. 8, 4, 463-476.

22 Sheng J.J. (2013) Comparison of the effects of wettability alteration and IFT reduction on oil recovery in carbonate reservoirs, Asia-Pacific J. Chem. Eng. 8, 1, 154-161.

23 Landa-Marbán D., Radu F.A., Nordbotten J.M. (2017) Modeling and simulation of microbial enhanced oil recovery including interfacial area, Transp. Porous Med. 120, 2, 395-413.

24 Bailey S.A., Kenney T.M., Schneider D.R. (2001) Microbial enhanced oil recovery: diverse successful applications of biotechnology in the oil field, in: SPE Asia Pacific Improved Oil Recovery Conference, 6-9 October, Kuala Lumpur, Malaysia, Society of Petroleum Engineers.

25 Afrapoli M.S., Crescente C., Alipour S., Torsaeter O. (2009) The effect of bacterial solution on the wettability index and residual oil saturation in sandstone, J. Pet. Sci. Eng. 69, 3-4, 255-260.

26 Zekri A.Y., Ghannam M.T., Almehaideb R.A. (2003) Carbonate rocks wettability changes induced by microbial solution, in: SPE Asia Pacific Oil and Gas Conference and Exhibition, 9-11 September, Jakarta, Indonesia, Society of Petroleum Engineers.

27 Armstrong R.T., Wildenschild D. (2012) Investigating the pore-scale mechanisms of microbial enhanced oil recovery, $J$. Pet. Sci. Eng. 94, 155-164.

28 Armstrong R.T., Wildenschild D. (2012) Microbial enhanced oil recovery in fractional-wet systems: A pore-scale investigation, Transp. Porous Med. 92, 3, 819-835.

29 Brown L.R., Vadie A.A., Stephens J.O. (2000) Slowing production decline and extending the economic life of an oil field: new MEOR technology, in SPE/DOE Improved Oil Recovery Symposium, 3-5 April, Tulsa, Oklahoma, Society of Petroleum Engineers.

30 Jiecheng C., Wei L., Jingyuan Z., Junzheng W., Zhenyu Y., Cuiling G. (2007) Studies on the Pilot Test with microbial profile modification after polymer flooding in Daqing Oilfield, in: IPTC 200\%: International Petroleum Technology Conference, 7-8 May, Dhahran, Saudi Arabia. https://doi.org/ 10.3997/2214-4609-pdb.147.iptc11227.

31 Jinfeng L., Lijun M., Bozhong M., Rulin L., Fangtian N., Jiaxi Z. (2005) The field pilot of microbial enhanced oil recovery in a high temperature petroleum reservoir, J. Pet. Sci. Eng. 48, 3-4, 265-271.

32 Kowalewski E., Rueslatten I., Boassen T., Sunde E., Stensen J.A., Lillebo B.-L., Gunhild B., Torsvik T. (2005) Analyzing microbial improved oil recovery processes from core floods, in: International Petroleum Technology Conference, 21-23 November, Doha, Qatar, International Petroleum Technology Conference.

33 Karim M.G., Hj Salim M.A., Md. Zain Z., Talib N.N. (2001) Microbial Enhanced Oil Recovery (MEOR) technology in Bokor Field, Sarawak, in: SPE Asia Pacific Improved Oil Recovery Conference, 6-9 October, Kuala Lumpur, Malaysia, Society of Petroleum Engineers.

34 Sen R. (2008) Biotechnology in petroleum recovery: the microbial EOR, Prog. Energy combust. Sci. 34, 6, 714-724.

35 Al-Hattali R.R., Al-Sulaimani H.S., Al-Wahaibi Y.M., Al-Bahry S., Elshafie A., Al-Bemani A.S., Joshi S. (2012) Improving sweep efficiency in fractured carbonate reservoirs by microbial biomass, in: SPE EOR Conference at Oil and Gas West Asia, 16-18 April, Muscat, Oman, Society of Petroleum Engineers.

36 Biria D., Roostaazad R., Darouneh E., Izadi H. (2007) Analysis of MEOR efficiency to increase recovery in an Iranian reservoir, Scientia Iranica 14, 2, 161-168.

37 Nourani M., Panahi H., Mohebbi A., Haghighi M., Roostaazad R., Biria D. (2007) Laboratory studies of MEOR in the micromodel as a fractured system, in: Eastern Regional Meeting, 17-19 October, Lexington, Kentucky, Society of Petroleum Engineers.

38 Salehizadeh H., Mohammadizad S. (2009) Microbial enhanced oil recovery using biosurfactant produced by Alcaligenes faecalis, Iranian J. Biotechnol. 7, 4, 216-223.

39 Soudmand-Asli A., Ayatollahi S.S., Mohabatkar H., Zareie M., Shariatpanahi S.F. (2007) The in situ microbial enhanced oil recovery in fractured porous media, J. Pet. Sci. Eng. 58, 1-2, 161-172.

40 Zekri A.Y., Almehaideb R. (2003) Microbial and waterflooding of fractured carbonate rocks: An experimental approach, Pet. Sci. Technol. 21, 1-2, 315-331.

41 Xiao M., Zhang Z.-Z., Wang J.-X., Zhang G.-Q., Luo Y.-J., Song Z.-Z., Zhang J.-Y. (2013) Bacterial community diversity in a low-permeability oil reservoir and its potential for enhancing oil recovery, Bioresour. Technol. 147, 110-116.

42 Kazemi H. (1969) Pressure transient analysis of naturally fractured reservoirs with uniform fracture distribution, SPE J. 9, 04, 451-462.

43 Warren J.E., Root P.J. (1963) The behavior of naturally fractured reservoirs, SPE J. 3, 03, 245-255.

44 Lanning L.M., Ford R.M. (2002) Glass micromodel study of bacterial dispersion in spatially periodic porous networks, Biotechnol. Bioeng. 78, 5, 556-566.

45 Fan Y.Q., Gao K., Chen J., Li W.G., Zhang Y. (2018) Lowcost PMMA-based microfluidics for the visualization of enhanced oil recovery, Oil Gas Sci. Technol. - Rev. IFP Energies nouvelles $\mathbf{7 3}, 26$.

46 Tsakiroglou C.D., Avraam D.G. (2002) Fabrication of a new class of porous media models for visualization studies of multiphase flow processes, J. Mater. Sci. 37, 2, 353-363.

47 Robin M. (2001) Interfacial phenomena: reservoir wettability in oil recovery, Oil Gas Sci. Technol. - Rev. IFP Energies nouvelles 56, 1, 55-62.

48 Didari M., Amoozegar M.A., Bagheri M., Mehrshad M., Schumann P., Spröer C., Sanchez-Porro C., Ventosa A. (2013) Bacillus persicus sp. nov., a halophilic bacterium from a hypersaline lake, Int. J. Syst. Evol. Microbiol. 63, 1229-1234.

49 Mukerjee P., Mysels K.J. (1971) Critical micelle concentrations of aqueous surfactant systems, National Standard reference data system. 